\title{
Clinical and epidemiological survey and analysis of the first case of human infection with avian influenza $A(H 7 N 9)$ virus in Hangzhou, China
}

\author{
L. Xie • H. Ding • Q.-J. Kao • X.-H. Yang • Y.-Y. Wen • \\ H.-K. Lv • Z.-P. Chen • E.-F. Chen • Z. Sun • J.-C. Pan • \\ X.-Y. Pu • J. Li • F.-J. Wang • X.-P. Xu
}

Received: 8 May 2013 / Accepted: 27 June 2013 / Published online: 30 August 2013

(C) The Author(s) 2013. This article is published with open access at Springerlink.com

\begin{abstract}
To investigate and report on the clinical and epidemiological characteristics of the first case of human infection with avian influenza A(H7N9) virus in Hangzhou, China. A field epidemiological survey was used to study the first case in Hangzhou. The patient was a 39-year-old male chef with a history of exposure to a farm product market and to poultry prior to the onset of disease on 15 March 2013. He had diarrhea, chills, pyrexia, and intermittent cough with freshly red foamy bloody sputum early in his disease. His fever $>39^{\circ} \mathrm{C}$ continued for a week with rapid progression. Computed tomography findings showed extensive bilateral consolidation, followed by multiorgan failure. The patient died on the morning of 27 March. His infection was eventually confirmed 1 week later on 3 April. Flu-like symptoms including fever and cough were found in 46 of his 138 close contacts. This was the first case of human infection with avian influenza A(H7N9) virus in Hangzhou. None of the close contacts had onset of the disease. The case patient's
\end{abstract}

Li Xie and Hua Ding authors contributed equally to this work.

L. Xie $\cdot$ H. Ding $\cdot$ Q.-J. Kao $\cdot$ X.-H. Yang $\cdot$ Y.-Y. Wen $(\bowtie) \cdot$

Z. Sun $\cdot$ J.-C. Pan $\cdot$ X.-Y. Pu $\cdot$ J. Li

Hangzhou Center for Disease Control and Prevention,

Hangzhou City 310021, Zhejiang Province, China

e-mail: wenyuanyuan1022@126.com

H.-K. Lv · Z.-P. Chen • E.-F. Chen

Zhejiang Center for Disease Control and Prevention,

Hangzhou, China

F.-J. Wang

Xiaoshan District Center for Disease Control and Prevention,

Hangzhou, China

X.-P. Xu

Jiande District Center for Disease Control and Prevention,

Hangzhou, China condition progressed rapidly. The source of infection might be his exposure to the farm product market, but the mode of exposure remains unclear.

\section{Introduction}

Cases of avian influenza A(H7N9) virus infection were first reported in Shanghai and Anhui, China, in March 2013 [1,2]. Human infections with influenza A (H7) viruses have been reported sporadically, but infection of H7N9 in humans has never been documented before [3, 4]. On 24 March 2013, the First People's Hospital of Xiaoshan District, Hangzhou City reported admission of a patient with pyrexia and a cough, later complicated by severe pneumonia and multiorgan failure. The patient died eventually from multiorgan failure 12 days after disease onset and was confirmed as having had H7N9 virus infection 1 week later. The clinical and epidemiological investigation and response measures are reported as follows.

\section{Materials and methods}

Case survey

The epidemiological case survey was conducted according to the Prevention and Control Protocol for Human Infections with Avian Influenza A(H7N9), 1st edition, issued by the National Health and Family Planning Commission (NHFPC) of the People's Republic of China, to trace the infection sources, observe the patient's close contacts, and to disinfect his household. Criteria in the Diagnosis and Treatment Protocol for Human Infections with Avian Influenza A(H7N9, 1st edition, 2013) were referred to for diagnosis and management of the case $[5,6]$. 


\section{Data collection}

We used a standard surveillance report form to collect the epidemiological and clinical data on the case, including his demographic information, visits to medical facilities, hospitalization, clinical outcome, recent exposures to poultry or other animals, and other relevant epidemiological information.

Follow-up of close contacts

Close contacts of the H7N9 patient were identified according to the criteria defined in the field survey of H5N1 influenza [7]. Once they were identified, the close contacts were followed up for the presence of symptoms with daily telephone calls for 7 consecutive days. Throat swabs were collected from the close contacts with symptoms such as fever and a cough and were tested for H7N9 virus.

Auxiliary examinations

Results of the patient's blood routine, biochemistry, and chest radiography work-up were collected.

\section{Results}

\section{Demographic information}

The patient was a 38-year-old male chef, who worked in Jiangsu Province. His past history included obesity, hepatitis $\mathrm{B}$, and chronic cholecystitis.

\section{Clinical diagnosis and management}

The patient had chills, a fever $\left(39.5^{\circ} \mathrm{C}\right)$, and an intermittent cough with bright red foamy bloody sputum on 15 March 2013, but did not seek medical attention. He presented to the Emergency Department of a hospital in Jiande City on 18 March and was admitted for hepatitis. His blood test results on 19 March were WBC, 2.33*109 /L; CRP, 43.7 mg/L; AFP, $336.8 \mathrm{mg} / \mathrm{L}$; HBV, positive; and the chest radiography showed infection of the lower lobe of the right lung. The chest CT finding on 20 March indicated infection of the lower lobe of the right lung. He began to experience shortness of breath and hemoptysis on the evening of 20 March, was transferred to the Emergency Department of a hospital in Xiaoshan District at about 22:00 the same night, and admitted for lobar pneumonia. Chest CT findings indicated infectious changes in both lungs with pleural effusion in the right lung. The primary diagnosis of the local hospital was severe pneumonia, type I respiratory failure, and chronic viral hepatitis B. After hospitalization, he was given integrated management including respiratory isolation, combined antibiotic therapy, lamivudine for hepatitis B virus, liver and gastric protective treatments, and fluid infusion. No bacterial, fungal or other pathogenic organisms were found by sputum culture. No anti-viral medication such as oseltamivir was administered. Moist rales were heard all over the lungs on 27 March. His heart rate dropped suddenly to $68 \mathrm{bpm}$ on the morning of $27 \mathrm{March}$, with ABP of $40 / 16 \mathrm{mmHg}$ and massive bloody fluid aspirated from the airway. He died at 07:00 on 27 March after failed rescue. The total course of the disease was 12 days. An expert team from the Zhejiang Provincial Health Department confirmed the diagnosis of the first case of human infection with avian influenza A(H7N9) virus on 3 April 2013 according to his clinical presentation, epidemiological information, and test results. Figure 1 shows the clinical sequence.

Epidemiological investigation

\section{Epidemiological history}

The patient was a chef residing in Taicang City, Jiangsu Province. He had bought two chickens at a farm product market on the morning of 8 March, cooked them by braising, and ate the meat the next day. He went to the headquarters of his work affiliation in Xiaoshan, Hangzhou, Zhejiang Province by company car for a 2-day service training course and returned to Taicang by company car on the afternoon of 10 March. He walked $2 \mathrm{~km}$ to a farm product market to buy food ingredients on 11 and 12 March, where his exposure to poultry or vendor booths and mode of exposure were unclear. He had no visitors, travel history or contact with similar patients during the 2 weeks before disease onset.

\section{Dwelling environment}

The patient lived with his wife and son in two intercommunicating rooms $\left(30 \mathrm{~m}^{2}\right)$ in the building where he worked. The rooms were well illuminated and ventilated. The dwellers had good hygienic habits, and aired and cleaned the rooms every day. The building was surrounded by farmlands with no poultry farm or living garbage dump within a 2$\mathrm{km}$ radius.

\section{Survey of close contacts}

Epidemiological survey and screening identified 138 close contacts, including 29 family members and relatives, 18 colleagues, 6 patients sharing a ward, and 85 healthcare providers with unprotected contact. The close contacts were followed up for 7 consecutive days; flu-like symptoms were noted in 46 . Throat swabs were collected from the symptomatic close contacts and all tested negative for H7N9 virus nucleic acid. 


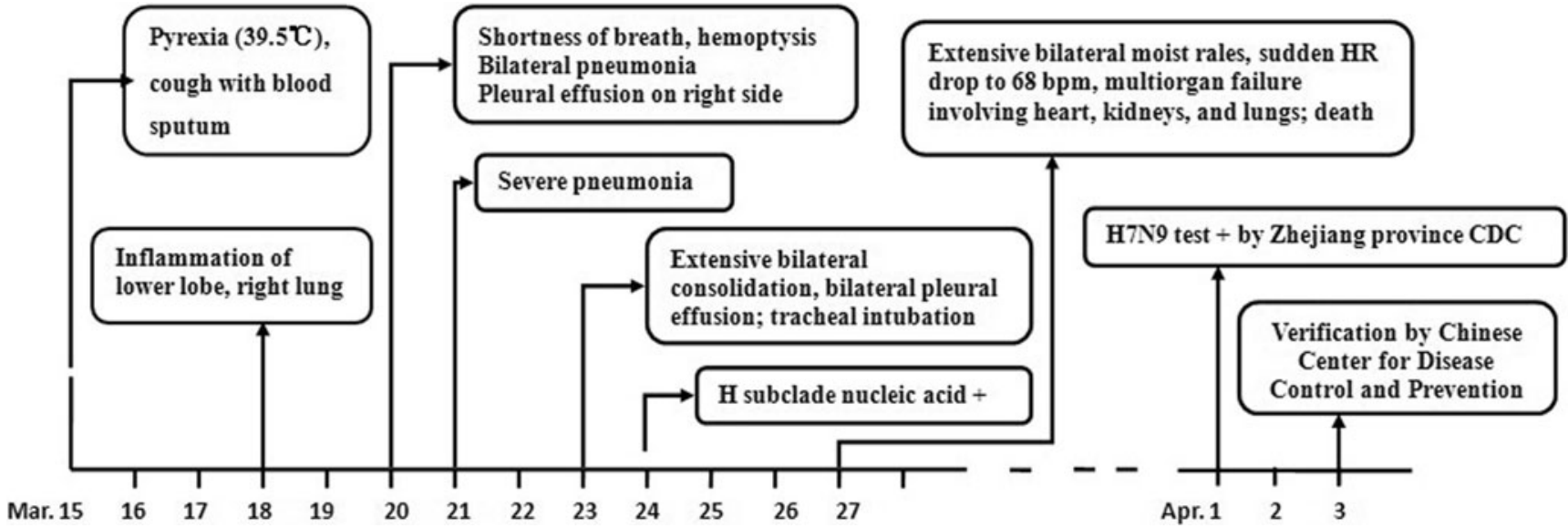

Fig. 1 Timeline of clinical symptoms, signs, and laboratory test results of the first H7N9 case in Hangzhou. 18-20 March: treated in the Second People's Hospital of Jiande; 21-24 and 25-27 March treated in the

Auxiliary examinations

The chest X-ray, chest $\mathrm{CT}$, and routine blood test results are shown in Table 1 and Fig. 2.

Prevention and control measures

Terminal disinfection was carried out in the places involved in the diagnosis and management processes. The corpse of the deceased was disinfected and treated for preservation before cremation 6 days later. Emergency surveillance for pneumonia with unknown causes was implemented, appropriate screening and triage practices were enforced at the medical facilities, diagnosis and treatment at the febrile respiratory clinics were standardized at all medical facilities and local health stations, and a zero and daily report mechanism was devised.

Table 1 Chest X-ray and routine blood test results of the patient during hospitalization

\begin{tabular}{|c|c|c|c|}
\hline \multirow{2}{*}{$\begin{array}{l}\text { Date of } \\
\text { examination }\end{array}$} & \multirow[t]{2}{*}{ Chest X-ray or chest CT } & \multicolumn{2}{|l|}{ Blood routine } \\
\hline & & $\operatorname{WBC}\left(10^{9} / \mathrm{L}\right)$ & $\mathrm{NE} \%$ \\
\hline 18 March & Infection in the right lower lobe & N/A & N/A \\
\hline $20 \mathrm{March}$ & $\begin{array}{l}\text { Infectious changes in both lungs, } \\
\text { pleural effusion in the right side }\end{array}$ & 1.6 & 78.4 \\
\hline 23 March & $\begin{array}{l}\text { Extensive bilateral consolidation, } \\
\text { bilateral pleural effusion }\end{array}$ & 4.2 & 80.1 \\
\hline 25 March & $\begin{array}{l}\text { Extensive exudative changes } \\
\text { in both lungs with unclear } \\
\text { diaphragmatic surface on } \\
\text { either side }\end{array}$ & 6.9 & 84.7 \\
\hline
\end{tabular}

The test results of 18 March were from the Second People's Hospital of Jiande City and the remaining were hospitalization test results from the First People's Hospital of Xiaoshan District

$W B C$ white blood cell count, $N E \%$ percentage of neutrophilic granulocytes, $N / A$ not available
Respiratory Disease Department and the ICU of the First People's Hospital of Xiaoshan District respectively

\section{Discussion}

The patient had a past history of obesity, hepatitis B, and chronic cholecystitis. When his symptoms first appeared, he overlooked them and failed to seek medical attention. His condition deteriorated rapidly. The clinical features were consistent with the H7N9 cases reported in Shanghai [2]. After hospitalization, no bacterial, fungal or other pathogenic organisms were found by sputum culture. No anti-viral medication such as oseltamivir was administered.

The patient went to the local farm product market for food ingredients, where his exposure was unclear. Given a typically 7-day incubation period of H7N9 infection, he could have been infected in his workplace, where the source of exposure

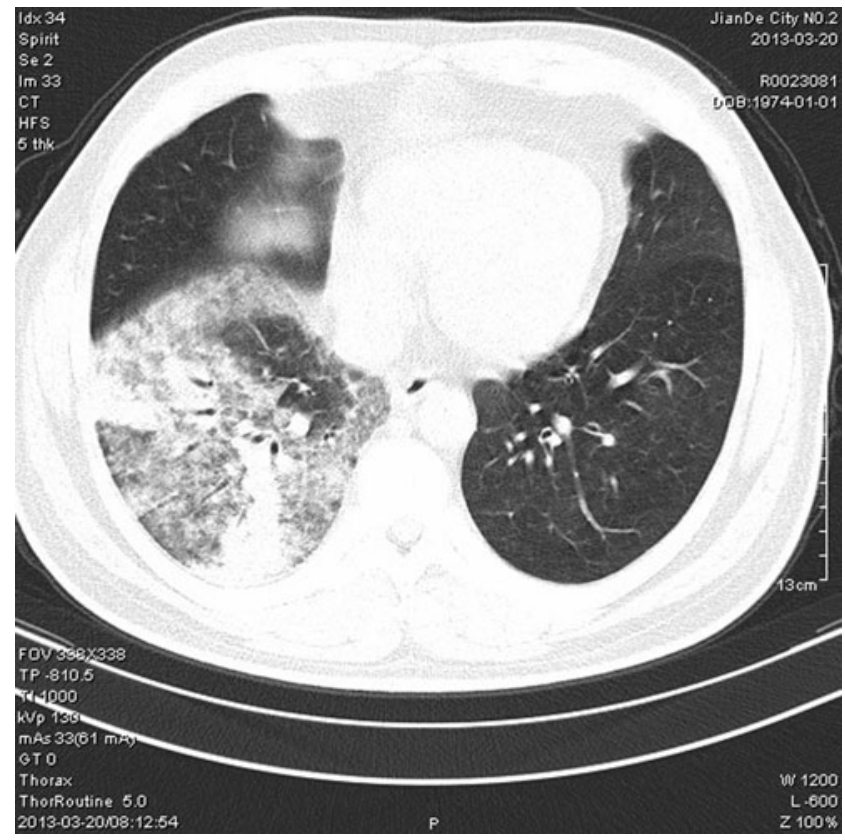

Fig. 2 Chest X-ray of the patient during hospitalization 
remains unidentified. It is thus suggested that Jiangsu Provincial CDC should be contacted for external environment sampling and testing. Timely investigation and result analysis for key information are crucial once human or animal influenza breaks out [8].

Prospective follow-up investigations of the close contacts have failed to conclusively establish human-to-human transmission of H7N9 virus from the confirmed cases [3]. However, reported non-sustained transmission of avian flu viruses between humans [9] and genetic mutation during genome replication $[10,11]$ are good reasons for Chinese health authorities and researchers to remain on high alert for potential emergence of human-to-human transmission.

Conflict of interest The authors declare that they have no conflict of interest.

Open Access This article is distributed under the terms of the Creative Commons Attribution License which permits any use, distribution, and reproduction in any medium, provided the original author(s) and the source are credited.

\section{References}

1. World Health Organization. Human infection with influenza A(H7N9) virus in China. Geneva: WHO: 2013. Available at: http://www.who.int/ csr/don/13_04_01/en/index.html.
2. Yang F, Wang J, Jiang L et al (2013) A fatal case caused by novel H7N9 avian influenza A virus in China. Emerg Microbes Infect 2:e19

3. Li Q, Zhou L, Zhou M et al (2013) Preliminary report: epidemiology of the Avian influenza A (H7N9) outbreak in China. N Engl J Med. doi:10.1056/NEJMoa1304617

4. Gao R, Cao B, Hu Y et al (2013) Human infection with a novel avian-origin influenza A (H7N9) virus. N Engl J Med 368(20):1888-1897

5. The National Health and Family Planning Commission (NHFPC) (2013) Diagnosis and treatment protocol for human infections with avian influenza A(H7N9), 1st edn. Available at: http:/www.moh. gov.cn/mohyzs/s3586/201304/839aecf249f94b5e90f03a3c 37471dd9.shtml.

6. The National Health and Family Planning Commission (NHFPC). The prevention and control protocol for human infections with avian influenza $\mathrm{A}(\mathrm{H} 7 \mathrm{~N} 9)$, 1st edn. Available at: http://www.moh.gov.cn/ mohjbyfkzj/s3578/201304/c1ab8ea6b2bf447dbfda724cc0afbb6e. shtml.

7. Wang H, Feng Z, Shu Y et al (2008) Probable limited person-toperson transmission of highly pathogenic avian influenza A (H5N1) virus in China. Lancet 371(9622):1427-1434

8. Mou J, Cheng J-Q, Zhang S, Ma H (2005) Quick telephone survey of human avian flu critical information and results analysis. Chin J Prev Med (05):426-427

9. Abdel-Ghafar A-N, Chotpitayasunondh T, Gao Z et al (2008) Update on avian influenza A (H5N1) virus infection in humans. N Engl J Med 358(3):261-273

10. Ilyushina NA, Govorkova EA, Webster RG (2005) Detection of amantadine-resistant variants among avian influenza viruses isolated in North America and Asia. Virology 341(1):102106

11. Olsen B, Munster VJ, Wallensten A, Waldenstrom J, Osterhaus A, Fouchier RAM (2006) Global patterns of influenza A virus in wild birds. Science 312(5772):384-388 